\title{
Analisis Karakteristik Perilaku Manusia Konteks Kitab Targhib Wa Tarhib As- Syeikh Husein (Hafidz Al-Mundziri)
}

\author{
Novira Arafah \\ novira.arafah2121@gmail.com \\ Institut KH. Abdul Chalim Mojokerto \\ Sarini Musyafi'ah Ali \\ sariniali6@gmail.com \\ Institut KH. Abdul Chalim Mojokerto \\ Syamsul Hadi \\ Institut KH. Abdul Chalim Mojokerto
}

Abstract:

This study was conducted to describe and measure: (1) Characteristics of human behavior (2) Behavior based on the concept of the book Targhib wa Tarhib AsSyeikh Husein. The type of research used is descriptive qualitative is literature study. The results of this study indicate: (1) The characteristics of human behavior indicate a variety of human behavior. This diversity depends on how it is managed. In this case, of course, humans as the center of the center (2) Characteristics of human behavior in the context of Targhib wa Tarhib is to explain the Islamic concept of how behavior can refer to the direction of reward and punishment. Does something deserve appreciation or refers to the negligence that caused the punishment to be given. In this way, the Islamic concept also recognizes that praiseworthy behavior can be imitated, so that it is entitled to praise, praise and appreciation, while on the contrary, it is the same.

Keywords: Characteristics, Human Behavior Context of the Targhib wa Tarhib As-Syeikh Husein's book

\section{Pendahuluan}

Dalam kehidupan manusia, pendidikan mengambil peran penting dalam keberadaannya untuk memberikan kemajuan generasi-ke generasi. Islam sendiri sangat memperhatikan pendidikan. Hal ini, selaras dengan salah satu hadits Nabi Saw., yang artinya: "menuntut ilmu itu wajib". Jadi sudah sangat jelas bahwa Islam juga sangat mengajurkan umatnya untuk memiliki ilmu pengetahuan. Tidak kalah dengan pendidikan umum, Islam juga hadir dengan membawa inovasi baru dalam pendidikan. Salah satunya dengan menghadirkan metode-metode yang tentu saja sudah lebih dahulu dijelaskan dalam Al-Quran. Dalam pelaksanaannya, pendidikan islam juga berorientasi pada pembentukkan karakter. Hal ini juga tercantum pada UU no 20 Tahun 2003: 
Pendidikan Nasional berfungsi mengembangkan kemampuan dan membentuk watak serta peradaban bangsa yang bermatabat dalam rangka mencerdaskan kehidupan bangsa, bertujuan untuk berkembangnya potensi peserta didik agar menjadi manusia yang beriman dan bertakwa kepada Tuhan Yang Maha Esa, berakhlak mulia, sehat, berilmu, cakap kreatif, mandiri dan menjadi warga Negara yang demokratis serta bertanggung jawab. ${ }^{1}$

Karakter atau akhlak merupaka fondasi yang penting yang harus ditanamkan kepada manusia. Oleh sebab itu, karakter mendapatkan tempat tersendiri dalam dunia pendidikan. Karakter merupakan masalah utama, sehingga membutuhkan perhatian khusus oleh pengampu pendidikan. Karena baik-buruknya perilaku manusia ditentukan oleh karakter masing-masing individu.

Dari uraian di atas, bisa kita Tarik benang merah bahwa untuk mencapai semua itu, pendidikan membutuhkan metode dan strategi untuk menunjang proses pendidikan. Berbicara tentang metode-metode dalam pendidikan, pendidikan umum sudah banyak menerapkan metode-metode yang dianggap mampu untuk meningkatkan kemampuan seseorang. Namun, metode-metode yang digunakan hanyalah sebatas pada mentrasfer ilmu pengetahuan semata.

Pendidikan Islam, juga memiliki banyak metode yang tentu saja sudah diterapkan sejak zaman Nabi Muhammad Saw., salah satunya adalah Metode targhib wa tarhib. Metode ini telah dijelaskan di dalam al-Quran. Dimana, Targhib memiliki arti hadiah atau reward dan tarhib adalah ancaman atau hukuman. Kedua metode ini digunakan untuk menjadikan manusia menjadi pribadi yang taat kepada Allah. Kedua hal ini, harus dilakukan secara bersamaan agar tujuannya bisa maksimal. ${ }^{2}$ Penggunaan metode Targhib wa tarhib ini diyakini mampu menanamkan dan meningkatkan karakteristik dengan sangat baik dan

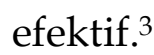

\section{Metode Penelitian}

Kajian ini menggunakan metode library research. Dimana, berdasar pendapat Sugiyono, metode penelitian kepustakaan merupakan kajian teoritis, referensi serta literature ilmiah lainnya yang berkaitan dengan budaya, nilai dan norma yang berkembang pada situasi social yang diteliti. Literatur yang digunakan tidak kurang dari 5 artikel yang masing-masing disampaikan secara tersendiri untuk

\footnotetext{
${ }^{1}$ Undang-Undang Ri Nomor 20 Tahun 2003, Sitem Pendidikan Nasional, Pasal 3 Ayat 1, n.d.

2 Fina Surya Anggraini, “Targhib Wa Tarhib Perspektif Al-Quran,” Jurnal Inovatif Vol 4, no. No.1 (2018): 141-65.

${ }^{3}$ Munawar Rahmat \& M. Abdul Shomad, "Studi Model Pembelajaran Targhib Wa Tarhib Dalam Perkuliahan PAI Untuk Pembinaan Karakter Anti Korupsi Pada Mahasiswa," JUrnal Pendidikan Agama Islam-Ta'lim Vol. 14, no. No.2 (2016): 127-38.
} 
mendapatkan gambaran yang jelas mengenai Karakteristik Perilaku Manusia Konteks Kitab Targhib Wa Tarhib. Literatur dipilih dari sumber yang masa publikasinya tidak lebih lama dari 10 tahun agar informasi yang didapat update disesuaikan oleh kondisi yang ada sekarang.

\section{Hasil Penelitian dan Pembahasan}

\section{Karakteristik dalam berperilaku}

Pertama kali, Teori Perilaku dikembangkan oleh B.F Skinner pada tahun 1950, Teori ini menggunakan konsep "positif" dan "negatif" untuk mengontrol perilaku seseorang. Sikap terhadap perilaku merupakan evaluasi subjektif (positif/negatif) berdasarkan keuntungan atau kerugian yang dirasakan dari perilaku tersebut. 4

Teori behavioristic menganalisis perilaku yang tampak, dapat diukur, diramalkan maupun dilukiskan. Dalam teori behavioristic ini sering disebut sebagai teori belajar sebagai seluruh aspek perilaku merupakan hasil belajar. Belajar berarti penguatan ikatan, asosiatif, sifat dan kecenderunagan perilaku (stimulus-respons), seperti gambar berikut:

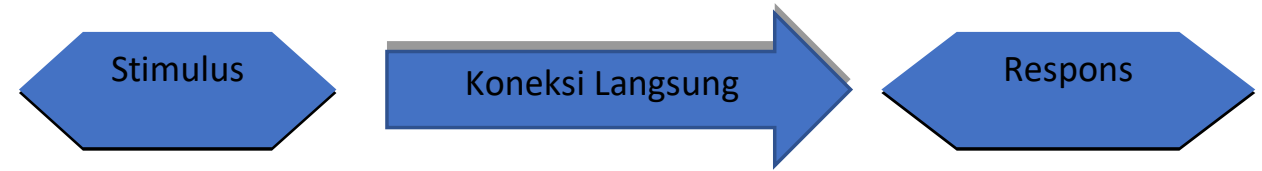

Gambar 1. Alur dalam berperilaku

Stimulus berarti lingkungan belajar baik internal maupun eksternal yang menjadi penyebab belajar. Sementara respons adalah dampak/akibar berupa reaksi fisik terhadap stimulus. Sebagai syarat karakteristik perilaku dalam pola hubungan S-R ialah adanya unsur: dorongan (drive), rangsangan (stimulus), respond an penguatan (reinforcement). Dengan demikian, dalam memperlajari karakteristik tingkah laku terdapat reaksi yang erat antara jalinan behavioural dengan stimulusnya. ${ }^{5}$

Benny mengutip pendapat Syamsu yusuf, yang mengartikan reinforcement sebagai "peneguhan", dimana peneguhan ini dibagi menjadi dua macam, yakni: (1) Peneguhan positif, yaitu suatu rangsangan (stimulus) yang memperkuat atau mendorong suatu respon (tingkah laku tertentu). Biasanya berupa ganjaran, hadiah, atau imbalan, baik dengan ungkapan verbal (kata-kata atau ucapan pujian) maupun non verbal (isyarat, senyuman, hadiah berupa bendabenda dan makanan), (2) Peneguhan negatif, yaitu suatu rangsangan (stimulus) untuk mendorong seseorang menghindari respon tertentu dimana konsekuensi

4 Tyas Palupi. Dian Ratna Sawitri, "Hubungan Antara Sikap Dengan Perilaku Pro-Lingkungan Ditinjau Dari Perspektif Theory Of Planned Behavior," Proceeding Biology Education Conference Vol. 14, no. No. 1 (2017): 214-17.

${ }^{5}$ Nur Syafi'ah Khotim, Modul Starategi Pembelajaran (Yogyakarta: Bening Pustaka, 2019), 5. 
atau dampaknya tidak memuaskan, menyakitkan atau tidak menyenangkan. Peneguhan ini bentuknya berupa hukuman.

Pemaknaan reward dan punishment merupakan rangkaian istilah yang dihubungkan dengan pembahasan reinforcement yang diperkenalkan oleh Thorndike dalam observasinya tentang trial-and eror yang mana menjadi landasan utama reinforcement (dorongan, dukungan). Adanya reinforcement, tingkah laku atau perbuatan individu semakin menguat, sebaliknya dengan absennya reinforcement berarti semakin melemahnya tingkah laku. ${ }^{6}$

Karakteristik merupakan hal yang muncul sebagai acuan dari berperilaku. Singkatnya, bagaimana biasanya karakter watak seseorang maka begitu lah yang akan muncul menjadi tingkah lakunya. Berperilaku dapat dipelajari, sebagaimana ungkapan pendapat di atas, hanya saja stimulus dan respons terjadi juga didasari dari diri seseorang sendiri. Bagaimana ia mengendalikan atas stimulus yang diterima, begitulah respons yang akan dihasilkan. Jadi tetap didasarkan pada keinginan, spontanitas, keadaan dan faktor yang mempengaruhi.

\section{Pola Human Behavioristik}

Behaviour (perilaku manusia) mempelajari tentang tingkah laku manusia. Banyak yang harus dipenuhi, menyangkut hobi, pekerjaan, kegiatan atau semua hal yang menyangkut aspek perilaku manusia. Sebab suatu perencanaan yang tidak didasarkan atas perilaku orang yang memakainya maka apabila perencanaan tersebut dilakukan pada akhirnya tidak dirasa sebagai suatu kenikmatan oleh pemakainya. Sementara manusia sebagai kesatuan materi dan non materi dari berbagai unsur yang tidak dapat dibagi-bagi/dipisah7.

Dalam suatu lingkungan, pola perilaku manusia adalah hasil dari proses interaksi manusia dengan lingkungannya yang melibatkan emosional individual dan sosial. Dalam menganalisa terhadap privasi dan kebutuhan sosialnya tersebut diperlukan pendekatan melalui seting perilaku. Konsep ini mengacu pada seting perilaku yang terdiri dari 3 komponen, diantaranya: fisik (desain), sosial (penggunaan), dan budaya. ${ }^{8}$ Terdapat sifat yang paling berkesan dalam diri manusia, sebagaimana ungkapan berikut: "kekuatan pribadi berasal dari kejujuran pada diri sendiri dan ketulusan pada orang lain, juga dari sifat bisa diandalkan, berani, peduli, kukuh dan kreatif". ${ }^{9}$

6 Benny Kurniawan, "Konsep Targhib Dan Tarhib Dalam Perspektif Teori Belajar Behavioristik," Institut Agama Islam Nahdlatul Ulama Kebumen : An-Nidzam Vol. 03, no. No 1 (2016): 113.

${ }^{7}$ Fathul Lubabin Nuqul, Pengaruh Lingkungan terhadap Perilaku Manusia, Nitari PDF Professional.

8 Dedi Hantono. Diananta Pramitasari, "Diananta Pramitasari, Aspek Perilaku Manusia Sebagai Makhluk Individu Dan Sosial Pada Ruang Terbuka Publik," Nature Vol. 5, no. No. 2 (2018): 85-93.

9 Biki Zulfikri Rahmat, "Corporate Social Responsibility Dalam Perspektif Etika Bisnis Islam," Amwaluna: Jurnal Ekonomi Dan Keuangan Syariah Vol.1, no. No. 1 (2017): 98-113. 
Manusia sebagai makhluk Allah yang paling sempurna mempunyai karakteristik dan perilaku yang sangat berbeda dengan makhluk lainnya sehingga Allah memberikan amanat kepadanya, "dan kami tidak menciptkan jin dan manusia" (QS. Adz Dzariat : 21), di sisi lain manusia dilahirkan tidak mengetahui apa-apa (QS. 2: 106). Makhluk ciptaan Allah yang paling mulia diantara makhluk ciptaan-Nya yang lain ialah manusia. Manusia diharuskan mengenal siapa yang menciptakan dirinya sebelum mengenal lainnya. Dalam pandangan kebendaan (materialis) manusia hanyalah merupakan sekepal tanah di bumi. Manusia dalam pandangan kaum materialism, tidak lebih dari kumpulan daging, darah, urat, tulang, urat-urat darah dan alat pencernaan. Akal dan pikiran dianggapnya barang benda, yang dihasilkan oleh otak. ${ }^{10}$

Pada dasarnya, kebutuhan inderawi bukanlah satu-satunya stimulus baginya. Sebab, manusia tidak semata-mata tersentuh oleh motivasi-motivasi duniawi saja. ${ }^{11}$ Sebagai contoh nyata yang sering terjadi, faktanya dalam kondisi manusia ditimpa musibah, manusia akan mengingat dan menyebut asma Allah, serta memohon ampun kepada Allah dalam kondisi apapun dan bagaimana pun dia melakukan. Yang ada dalam pikirannya adalah, agar kondisi buruk tadi lepas dari pundaknya. Kedua, keadaan berikutnya justru berbalik. Ketaatan sementara tadi menjadi keadaan semula. Keadaan dimana ia berada diposisi nyaman tanpa ada beban. Kalaupun ia masih mengingat Allah SWT, namun tentunya akan berkurang jika dibandingkan keadaan pertama tadi, ungkap Sapuri.

Pembentukan manusia unggul sangat ditentukan oleh proses pendidikan dasar hingga menengah. Sementara yang tidak berjenjang adalah lembaga pendidikan non formal seperti pesantren. ${ }^{12} \mathrm{Hal}$ ini memupuk kekhususan cara berfikir bahwa pendidikan baik non formal maupun formal terkadang tak menjamin perilaku baik yang akan diperkenalkan. Realitsnya, banyak seseorang yang berpendidikan, berilmu, mengecap bangku sekolah formal/pesantren tetapi tak menerapkan secara kaffah apa yang telah ia pelajari. Perilaku yang ditunjukkan sama persin seperti masyarakat awam umumnya. Inilah yang seharusnya menonggak kepribadian seseorang hingga berperilaku sesuai dengan norma tempat/adat dan budaya yang berlaku. Bukan mengaharapkan pandangan yang mulia atas dirinya tetapi menerapkan aspek yang telah dicapai sebagai cerminan pada manusia itu sendiri.

10 Muslimin, "Manusia Dan Karakteristiknya Menurut Al-Qur'an (Kajian Tafsir Tarbawi)," Jurnal Tribakti, Volume 27 Nomor 2 September 2016 Vol. 27, no. No. 2 (2016): 227-47.

${ }^{11}$ Sugeng Sejati, "Tinjauan Al Qur'an Terhadap Perilaku Manusia: Dalam Perspektif Psikologi Islam," IAIN Bengkulu : Syi'ar Vol. 2017, no. No. 1 (2017): 61-70.

12 Dudung Abdurrahman.et al., "KARAKTERISTIK MANUSIA IDEAL DALAM PERSPEKTIF ISLAM," Prosiding SNaPPSosial, Ekonomi, Dan Humaniora Vol. 5, no. No. 1 (2015): 487-94. 
Anggapan orang lain terkadang penting untuk dipertimbangkan sebagi kritik membangun guna perbaikan manusia, sebagaimana jurus sakti dalam dunia pendidikan bahwasannya: "Pendidikan adalah upaya memanusiakan manusia yang dimanusia oleh manusia yang telah termanusia". Dunia akademisi pasti tak asing lagi pada istilah ini. Oleh sebabnya, tak salah layaknya seseorang berangkapan baik pada seseorang yang terpejar, dan tugas beratnya ialah bagaimana ia menjadi benar-benar terpelajar dimunculkan dengan tabi'atnya pada lingkungan dan masyarakatnya.

\section{Karateristik Human Habituation}

Rahmayulis dan Nizar mengatakan bahwa manusia adalah makhluk kosmis yang sangat penting, sebab telah dilengakapi dengan semua pembawaan dan syarat-syarat yang diperlukan bagi pengemban tugas dan fungsinya sebagai makhluk Allah di muka bumi. Jika berbicara mengenai manusia ialah pasti pembicaraan tentang diri kita sendiri, suatu pembicaraan yang tidak pernah tuntas dan berakhir. Substansi manusia pada dasarnya terdiri dari aspek fisik yang terdiri dari struktur jismiyyah atau jasadiyyah; aspek psikis disebut dengan struktur ruhaniyah; dan aspek psikofisik disebut dengan struktur nafsaniyyah. Masing-masing aspek ini memmeiliki natur, potensi, hukum, dan ciri-ciri tersendiri. ${ }^{13}$

Sebaik-baik perilaku manusia seperti layaknya ungkapan cinta yang tertuang dalam Al-Qur'an surah (4), sebagaimana berikut: “Orang-orang mukmin yang duduk menganggur di rumah dan mereka yang bekerja dengan kekuatan untuk keperluan Tuhan dengan kekayaan dan badan mereka, tiadalah akan diperlakukan sama. Kepada mereka yang berusaha dengan rajin dengan badan dan dengan kekayaan, Allah telah menunjukkan satu derajat di atas mereka yang tinggal duduk di rumah. Baguslah berbuat bagi semuanya. Tetapi Allah menunjukkan satu pembalasan yang indah kepada orang-orang yang rajin, melebihi mereka yang tinggal duduk di rumah, pembalasan di dalam derajat dekat dengan-Nya dan kemurahan-Nya. Allah Maha Pengasih Lagi Maha Pemurah".Didukung oleh sabda Baginda Nabi yang mengucapkan: "Barang siapa mendapat makanan dengan suatu kepandaian atau pekerjaan, mereka telah menjadi sahabat Allah".14

Ditarik dari firman Allah dan sabda Rasulullah bahwa sebagai manusia dalam berperilaku pun ada tingkatan derajat yang dapat membedakan antara satu manusia dengan manusia lainnya. Dengan kata lain disebut sebagai suatu kehormatan. Benar bahwasannya tiada yang membedakan manusia sebagai

${ }^{13}$ Mulyadi, "HAKIKAT MANUSIA DALAM PANDANGAN ISLAM," Jurnal Al-Taujih Vol. 3, no. No. 1 (2017): 29-38.

${ }^{14}$ HOS. Tjokroaminoto, Islam Dan Sosialisme (Bandung: Sega Arsy, 2010), 97. 
makhluk-Nya selain daripada iman dan ketaqwaannya. Tetapi kata iman dan ketaqwaan bukan sebatas arti sempit yang sebatas menyangkut amal ibadah vertikal semata. Lebih luas dari itu cakupannya, termasuk hubungan horizontal yang tak dapat terelakkan sesama makhluk Allah di muka bumi. Untuk itu saling berlombalah mendapat ridho' Allah mencapai derajat mulia disisi-Nya dan mencapai tingkat yang baik disisi sesama ummat manusia, yakni kehormatan diri.

Perkembangan pola perilaku manusia digubah menjadi baik atau buruk ditinjau dari bagaimana karakter yang telah tertaman dan berproses secara alamiah oleh diri yang membentuk perilaku keseharian hingg menjadi kebiasaan (habit) yang secara berulang dilakukan. Manusia sendiri sebagai makhluk berakal berhak menentukan perilaku yang secara sadar maupun tanpa disadari akan ia munculkan. Oleh karena itu hal sepele/keadaan yang tiba-tiba terjadi pada dasarnya sudah terbentuk dalam diri.

4. Tinjauan Karakteristik Perilaku Manusia Konteks Kitab Targhib wa Tarhib Assyaikh Husein

Amatullah Armstorng dalam buku "Sufi Terminology (al-Qamus al-Sufi): The Mystic Language of Islam," menjelaskan bahwa ta' dỉb terbagi empat yaitu : 1) Ta'dīb adabul haq (pendidikan tata krama dalam kebenaran); 2) Ta'dīb adabul khidmah (pendidikan tata krama dalam pengabdian); 3) Ta'dīb adabul syariah (pendidikan tata krama dalam syariah); 4) Ta'dīb adabul shuhbah (pendidikan tata krama spiritual persahabatan), dimana merupakan usaha dari pembentukan tata krama. ${ }^{15}$

At-tarhib berupa larangan atau hal-hal yang harus dihindari dalam kegiatan dan perilaku, karena itu termasuk dari akhlak tercela. Sementara perintah dan arahan untuk selalu menyenangi perbuatan dan perilaku yang baik sebagaimana dicontohkan oleh Rasulullah dinamakan at-targhib. Konsep targhib wa tarhib sering dikenal dengan istilah reward and punishment, hanya saja di dalam targhib wa tarhib mengarah pada pembentukan lingkungan atau bi'ah yang kondusif dengan pengamalan nilai-nilai islami yang berupa perilaku yang mengarah kepada akhlak karimah yang wajib diikuti dan akhlak madhmumah yang wajib dijauhi. ${ }^{16}$

Targhib bertujuan untuk mencapai keseimbangan antara dunia dan akhirata, sebab secara umum Pendidikan Islam menegaskan bahwa manusia terdiri dari ruh dan fisik, sehingga ia berfungsi menundukkan kebiasaan manusia terhadap kebesaran Allah. Metode Targhib menjadi sangat penting,

${ }^{15}$ Syarifan Nurjan, Perilaku Delinkuensi Remaja Muslim (Yogyakarta: Samudra Biru (Anggota IKAPI), 2019), 57.

${ }^{16}$ Nurjan, 77. 
karena dengan begitu pendidik bisa menemukan dan memahami karakteristik peserta didik, sehingga dalam mendidiknya menjadi lebih mudah dengan menggunkaan metode keteladanan. Bukan hanya itu saja, tetapi dalam ajaran Islam juga kita dianjurkan untuk selalu berbuat baik dan melarangamar ma'ruf nahi munkar.

Sedangkan metode tarhib, diberikan dengan maksud bahwa pelaku kejahatan bisa mendapatkan hukuman sesuai dengan yang di perbuat. Penggunaan metode tarhib ini dimaksudkan agar memberikan efek jera kepada pelaku kejahatan. ${ }^{17}$

Dalam konteks pendidikan, hukuman digunakan untuk menunjukkan kebenaran dari perilaku yang menyimpang. Akan tetapi, kita tidak boleh memberikan hukuman fisik secara semena-mena, atau biasa disebut dengan main hakim sendiri. Dalam Islam, Rasulullah Saw., telah memberikan contoh, bagaimana seharusnya kita selaku umatnya memberikan hukuman kepada yang bersalah. Hal pertama yang harus dilakukan adalah memberikan arahan atau nasihat terkait apa yang dilakukannya. Dalam memberikan nasihat atau arahan ini, hendaklah kita bersikap lemah lembut agar apa yang dikatakan tidak menyakiti hati. Kemudian yang kedua adalah memberikan ancaman, dan tahap yang terakhir adalah memberikan hukuman. Hal ini menunjukkan bahwa, hukuman merupakan tahapan terakhir untuk menyadarkan seseorang dari perbuatan yang telah dilakukan. ${ }^{18}$

Terkait dengan metode Targhib wa tarhib, Ibnu Sina mengemukakan pendapatnya bahwa "hukuman atau tarhib kepada anak-anak patut diberikan apabila mereka melakukan kesalahan". ${ }^{19}$ Hal ini bertujuan untuk membentuk akhlak pribadi diri, mendidik disiplin, serta memberi kesadaran dalam diri mereka. Setiap hukuman yang diberikan juga dapat mendidik anak-anak supaya mereka nantinya dapat meneliti terlebih dahulu apa akibat dari kesalahan yang mereka lakukan, sehingga secara tidak langsung mereka akan lebih berhati-hati dari melakukan kesalahan. ${ }^{20}$

Penggunaan metode ini, didasarkan pada tingkat kesadaran manusia yang berbeda. Disatu pihak ada yang sadar hanya dengan memberikan nasehat berupa pemberian reward dan dipihak yang lain ada juga yang akan sadar dan berubah apabila diberikan hukuman atau ancaman. Hal inilah yang membentuk

\footnotetext{
${ }^{17}$ Anggraini, "Targhib Wa Tarhib Perspektif Al-Quran."

18 Ma'rufin, "METODE TARGHIB DAN TARHIB (Reward Dan Punishment Dalam Pendidikan Islam)," Jurnal Risaalah, Vol . 1, No. 1, Desember 2015 Vol. 1, no. No. 1 (2015): 67-77.

19 Rahman Assegaf, Aliran Pemikiran Pendidikan Islam Hadharah Keilmuan Tokoh Klasik Sampai Modern (Jakarta: PT. Raja Grafindo, 2012), 97.

20 Iswati, "POLA PENERAPAN METODE TARGHIB WA TARHIB PADA PEMBELAJARAN TAHSIN TAHFIDZ DI SMPIT BINA INSANI KOTA METRO,” At-Tajdid Vol.2, no. No.2 (2018): 170-87.
} 
karakteristik perilaku manusia sangat beragam. Sehingga dalam pemberian dua metode ini, harus seimbang. Agar setiap pribadi bisa mengambil ibrah dalam setiap apa yang dikerjakan.

\section{Kesimpulan}

Karakteristik perilaku manusia menunjukkan kenyataan perilaku manusia yang beragam. Keberagaman tersebut tergantung bagaimana pengelolaannya. Dalam hal ini tentu saja manusia sebagai pusat centre dari aktivitas yang membentuk karakteristik hingga teraplikasi melalui perilaku keseharian manusia. Kesemuanya tentu saja dilandasi dengan atau tanpa kesadaran. Dengan kesadaran dilakukan dengan keinginan, kebiasaan dan keseleraan pelaku, dan tanpa kesadaran dapat ditemukan melalui aktivitas spontan, terkejut dan tanpa direncanakan sebelumnya.

Karakteristik perilaku manusia pada konteks Targhib wa Tarhib ialah menjelaskan konsep islam bagaimana perilaku yang dapat merujuk pada arah reward and punishment. Apakah sesuatu itu layak mendapat apresiasi atau merujuk pada ketidakbaikan yang menyebabkan hukuman yang akan diberikan. Demikian tergantung kepada pelaku serta perilaku yang ditunjukkan.

\section{Daftar Pustaka}

Anggraini, Fina Surya. “Targhib Wa Tarhib Perspektif Al-Quran.” Jurnal Inovatif Vol 4, no. No.1 (2018): 141-65.

Assegaf, Rahman. Aliran Pemikiran Pendidikan Islam Hadharah Keilmuan Tokoh Klasik Sampai Modern. Jakarta: PT. Raja Grafindo, 2012.

Dedi Hantono. Diananta Pramitasari. "Diananta Pramitasari, Aspek Perilaku Manusia Sebagai Makhluk Individu Dan Sosial Pada Ruang Terbuka Publik." Nature Vol. 5, no. No. 2 (2018): 85-93.

Dudung Abdurrahman.et al. "KARAKTERISTIK MANUSIA IDEAL DALAM PERSPEKTIF ISLAM." Prosiding SNaPPSosial, Ekonomi, Dan Humaniora Vol. 5, no. No. 1 (2015): 487-94.

Iswati. "POLA PENERAPAN METODE TARGHIB WA TARHIB PADA PEMBELAJARAN TAHSIN TAHFIDZ DI SMPIT BINA INSANI KOTA METRO." At-Tajdid Vol.2, no. No.2 (2018): 170-87.

Khotim, Nur Syafi'ah. Modul Starategi Pembelajaran. Yogyakarta: Bening Pustaka, 2019.

Kurniawan, Benny. "Konsep Targhib Dan Tarhib Dalam Perspektif Teori Belajar Behavioristik." Institut Agama Islam Nahdlatul Ulama Kebumen : An-Nidzam Vol. 03, no. No 1 (2016): 113.

Ma'rufin. “METODE TARGHIB DAN TARHIB (Reward Dan Punishment Dalam Pendidikan Islam)." Jurnal Risaalah, Vol . 1, No. 1, Desember 2015 Vol. 1, no. No. 
1 (2015): 67-77.

Mulyadi. "HAKIKAT MANUSIA DALAM PANDANGAN ISLAM." Jurnal AlTaujih Vol. 3, no. No. 1 (2017): 29-38.

Munawar Rahmat \& M. Abdul Shomad. "Studi Model Pembelajaran Targhib Wa Tarhib Dalam Perkuliahan PAI Untuk Pembinaan Karakter Anti Korupsi Pada Mahasiswa." JUrnal Pendidikan Agama Islam-Ta'lim Vol. 14, no. No.2 (2016): 127-38.

Muslimin. "Manusia Dan Karakteristiknya Menurut Al-Qur'an (Kajian Tafsir Tarbawi)." Jurnal Tribakti,Volume 27 Nomor 2 September 2016 Vol. 27, no. No. 2 (2016): 227-47.

Nurjan, Syarifan. Perilaku Delinkuensi Remaja Muslim. Yogyakarta: Samudra Biru (Anggota IKAPI), 2019.

Sejati, Sugeng. “Tinjauan Al Qur'an Terhadap Perilaku Manusia: Dalam Perspektif Psikologi Islam." IAIN Bengkulu : Syi'ar Vol. 2017, no. No. 1 (2017): 61-70.

Tjokroaminoto, HOS. Islam Dan Sosialisme. Bandung: Sega Arsy, 2010.

Tyas Palupi. Dian Ratna Sawitri. “Hubungan Antara Sikap Dengan Perilaku ProLingkungan Ditinjau Dari Perspektif Theory Of Planned Behavior,." Proceeding Biology Education Conference Vol. 14, no. No. 1 (2017): 214-17.

Undang-Undang Ri Nomor 20 Tahun 2003, Sitem Pendidikan Nasional, Pasal 3 Ayat 1, n.d.

Zulfikri Rahmat, Biki. "Corporate Social Responsibility Dalam Perspektif Etika Bisnis Islam." Amwaluna: Jurnal Ekonomi Dan Keuangan Syariah Vol.1, no. No. 1 (2017): 98-113. 